\title{
Polycyclic Aromatic Hydrocarbons and Carbon Isotopes in a Palsa Peat (Bol'shezemel'skaya Tundra)
}

\author{
Yu. K. Vasil'chuk ${ }^{a,}$ *, A. D. Belik ${ }^{a}$, N. A. Budantseva ${ }^{a}$, A. N. Gennadiev ${ }^{a}$, A. C. Vasil'chuk ${ }^{a}$, \\ J. Yu. Vasil'chuk ${ }^{a}$, Yu. A. Zavgorodnyaya ${ }^{a}$, A. P. Ginzburg ${ }^{a}$, and L. B. Bludushkina ${ }^{a}$ \\ ${ }^{a}$ Lomonosov Moscow State University, Moscow, 119991 Russia \\ *e-mail:vasilch_geo@mail.ru
}

Received November 7, 2020; revised December 23, 2020; accepted December 28, 2020

\begin{abstract}
The content of polycyclic aromatic hydrocarbons (PAHs) and carbon isotope composition in the peat of a palsa near Eletsky settlement, Vorkuta urban district, Komi Republic are analyzed. The carbon isotope composition of peat varies from -28.05 to $-30.05 \%$ (average $-29.15 \%$ ). The total PAH content varies from 11 to $360 \mathrm{ppb}$, with an average of $63 \mathrm{ppb}$ and a median value of $34 \mathrm{ppb}$. Heavy compounds, such as benzo $(a)$ anthracene and benzofluoranthenes, are prevalent among PAHs. The presence of PAHs in the peat is determined by three main factors: technogenic impact, wildfires, and biogeochemical soil processes. The prevalence of benzo $(a)$ anthracene in the upper part of the palsa down to the bottom of the active layer suggests an anthropogenic impact (the influence of transport and domestic fuel combustion). The share of benzo $(a)$ anthracene decreases with depth, while the share of benzofluoranthenes increases. Two sharp peaks of PAH content (260 and $360 \mathrm{ppb)} \mathrm{are} \mathrm{observed;} \mathrm{they} \mathrm{coincide} \mathrm{with} \mathrm{a} \mathrm{local} \mathrm{increase} \mathrm{of} \mathrm{carbon} \mathrm{isotope} \mathrm{values,}$ most likely resulting from wildfires. The minimums in PAH content are presumably determined by the biogeochemical factor and the input of polyarenes generated by decomposition of plant residues. Carbon isotope composition of peat mainly reflects the isotope composition of vegetation, the degree of peat moistening, and the influence of pyrogenic factor.
\end{abstract}

Keywords: polyarenes, paleoenvironment, wildfires, stable carbon isotopes, Dystric Histosols

DOI: $10.1134 / \mathrm{S} 1064229321070139$

\section{INTRODUCTION}

The permafrost peat mounds are commonly referred to as palsa, a Lappish word denoting a peat or a peat-mineral convex mound formed by peat or typically fine mineral sediments covered with peat and having a frozen core. In Russian studies, these mounds are also referred to as "migrational" mounds since their ice core formed of schlieren and thin lenses of segregated ice develops during soil moisture migration from an adjacent bog or the atmospheric precipitation filtering to the freezing front, i.e., to the formed core. The peat of palsa can be regarded as an archive of the data reflecting the natural conditions at the time they were formed and the corresponding technogenic impacts. The carbon isotope composition of peat as well as polycyclic aromatic hydrocarbons (PAHs) and other biomarkers of peat layer are the particular indicators of these conditions [26,30].

The products of biomass combustion [27] and the plant residues transformed by soil processes are the likely sources of PAHs in the palsa peat. For example, natural paleofires were identified according to the presence of heavy PAHs (pyrene, fluoranthene, benzofluoranthenes, and some other compounds) in bur- ied soils [36]. The effect of pyrogenic factor is frequently assessed using diagnostic $\mathrm{PAH}$ ratios (for example, see [17]) based on different energy expenditures during formation of individual compounds.

A natural biogeochemical origin of PAHs is also possible. Although our knowledge about this phenomenon is rather vague, polyarenes are abundant in the landscapes unaffected by anthropogenic activities [8, $9,12,13,16]$. As has been shown [11], light polyarenes (3-ring phenanthrene and its alkyl derivatives) are prevalent in the PAH composition of peat bodies under natural conditions. The authors [11] proposed an indicator of the natural biotransformation potential of soils towards PAHs as the ratio of phenanthrene to its derivatives.

The carbon isotope composition of peat is in many respects inherited from vegetation [14, 29] and depends on the temperature during the vegetation season as well as on the water abundance in bogs and on the specific features in the decomposition of plant residues. The isotope signal of the peat-forming plants mainly varies from $-20 \%$ in oligotrophic mosses to $-29 \%$ in plants of sedge family (Cyperaceae Juss.) [21]. The leaves of Cyperaceae Juss. plants are enriched in ${ }^{13} \mathrm{C}$ as 
compared with shrubs, while the range of $\delta^{13} \mathrm{C}$ values in sphagnum mosses is from -25.0 to $-29.6 \%$ [35]. As has been shown [21], the peat under conditions of aerobic organic matter decomposition usually displays a considerable decrease in $\delta^{13} \mathrm{C}$ values with depth (because of a stronger ${ }^{12} \mathrm{C}$ depletion in older deeper layers caused by emission). As for anaerobic soil destruction, either $\delta^{13} \mathrm{C}$ values insignificantly increase with depth or remain constant because of the slowing down of the microbiological processes in deeper layers. Thus, the ${ }^{12} \mathrm{C}$ and ${ }^{13} \mathrm{C}$ distributions in Histosols and peat deposits reflect the total effect of stable isotope fractionation processes during photosynthesis and microbiological decomposition. Commonly, uniform distribution or slow increase in $\delta^{13} \mathrm{C}$ values with the depth indicate young soils [19, 22-24, 28].

The goal of this work was to find specific features in the distributions of ${ }^{13} \mathrm{C}$ isotopes and PAHs in the palsa peat and to clarify the genesis of these phenomena. The following tasks were set: (1) to analyze the specific features in the contents of PAHs and carbon isotopes in palsa profile and (2) to find the sources of PAHs entering the palsa peat and to clarify the dynamics of carbon isotope composition.

\section{OBJECTS AND METHODS}

Location and natural conditions of the study area. A peat palsa located in the northeastern part of the Bol'shezemel'skaya tundra, within a palsa mire near Eletsky settlement (Fig. S1) at a distance of $1.5 \mathrm{~km}$ to the east of the settlement and $500 \mathrm{~m}$ from the railroad was examined in detail; its height is $3.5 \mathrm{~m}$; diameter is $10 \mathrm{~m}$; and slope gradients are up to 15 degrees (Fig. S2). The palsa is covered with moss-grass vegetation with dwarf shrubs (sphagnum, common haircap moss, sedges, and dwarf birch). According to radiocarbon dating, the age of the palsa is over 6400 years [3, 4].

A large part of the territory is hilly with low flattopped mounds, hill chains, and shallow hollows separating them; the hollows have gentle slopes and wide bottoms, which are typically occupied by lakes, bogs, and peatlands with palsas.

The climate is subarctic moderately continental; summer is short and cold; and winter is abundant in snow, long, and severe. The climate is formed under conditions of low solar radiation in winter and the influence of northern seas and intensive western airflow. The warm sea air outflow caused by Atlantic cyclones and frequent invasions of the air from the Arctic Ocean makes the weather unstable throughout the year [10].

The annual temperature amplitude is $32.7^{\circ} \mathrm{C}$. July is the warmest month of the year (mean monthly temperature is $+12.4^{\circ} \mathrm{C}$ ) and the coldest is January (mean monthly temperature is $-20.3^{\circ} \mathrm{C}$ ). The mean annual temperature is $-6.0^{\circ} \mathrm{C}$. The number of days with mean daily temperatures exceeding $0^{\circ} \mathrm{C}$ is 125 .
The snow cover thickness increases from November to January (these are the months with the most frequent cyclones). The thickest snow cover is reached by the second decade of March and amounts to $75 \mathrm{~cm}$ [10].

The landscapes of the territory belong to the southern tundra undulating hilly plains with a silt loam cover and moraine bedding and the southern tundra and forest-tundra upland and undulating foothills of the Subpolar Urals [10].

The vegetation is composed of tundra plant species, mosses, herbs, and dwarf shrubs, such as sphagnum, common haircap moss (Politrichum commune), European blueberry (Vaccinium myrtillus), bog bilberry ( $V$. uliginosum), cloudberry (Rubus chamaemorus), dwarf birch (Betula nana), and various sedge (Carex) species.

The prevalent soil types are Cryosols and Histosols. The study territory resides within the Pechora Plain in the southern tundra subzone, Bol'shezemel'skaya province, and Vorkuta district of the tundra surface-gley and peat-gley frozen soils $[1,6]$. Stagnant overwetting by surface water with formation of Histosols over large areas is frequently observed on flat ridges. Better surface drainage leads to formation of various soil associations and mosaic complexes of semihydromorphic and automorphic soils [1, 6].

Field methods. The study was performed in the late September of 2019 and 2020, when the seasonal thawing reached the maximum depth of 80 to $100 \mathrm{~cm}$. A $100-\mathrm{cm}$-deep soil profile was excavated on the top of the palsa. The soil there belongs to oligotrophic peat soils (Dystric Histosols). The thawed peat was sampled from the profile with intervals of $1-3 \mathrm{~cm}$ and sampled for the stable carbon isotope and PAHs analyses. Five samples of frozen peat to the depth of $140 \mathrm{~cm}$ were taken by drilling (using a Bosch electric ice drill).

Stable carbon isotope measurements were performed during 1-6 months after sampling. Peat samples were dried at temperature of approximately $25-$ $30^{\circ} \mathrm{C}$, comminuted, and sieved (mesh, $0.25 \mathrm{~mm}$ ). The isotope composition was determined for total peat carbon $[5,33,34]$.

Carbon isotope composition was determined at the Isotope Laboratory with the Faculty of Geography, Moscow State University, in a Delta-V Plus isotope ratio mass spectrometer with a standard EA $1112 \mathrm{HT}$ $\mathrm{O} / \mathrm{H}-\mathrm{N}$ element analyzer. The IAEA-CH-3, IAEACH-6, IAEA-600, and USGS-24 international standards were used for the calibration. The measurement accuracy of $\delta^{13} \mathrm{C}$ was $\pm 0.2 \%$.

PAHs were analyzed by high performance liquid chromatography. The preparation of samples started from the extraction with dichloromethane $(20 \mathrm{~mL}$ per $1 \mathrm{~g}$ dry peat). The resulting extract was filtered, evaporated, re-extracted with hexane, and purified using modified silica gel Diapak-C cartridges. The air-evaporation was performed to dryness. The purified extracts were also evaporated and re-extracted with 
Table 1. Total PAHs and calculated PAHs indicator ratios in peat

\begin{tabular}{c|c|c|c|c}
\hline \multirow{2}{*}{ Sample ID } & \multirow{2}{*}{ Depth, cm } & Total PAHs, ppb & \multicolumn{2}{|c}{ Indicator ratios [17] } \\
\cline { 3 - 4 } & & & Anthracene/phenanthrene & $\begin{array}{c}\text { Fluoranthene/ } \\
\text { [fluoranthene + pyrene] }\end{array}$ \\
\hline 1 & $0-3$ & 42.39 & 0.14 & 0.69 \\
2 & $6-9$ & 9.73 & - & 0.97 \\
3 & $12-15$ & 33.38 & 0.25 & 0.84 \\
4 & $15-18$ & 12.33 & 0.82 & 0.57 \\
5 & $18-21$ & 28.44 & 0.02 & 0.67 \\
6 & $24-27$ & 34.44 & - & 0.80 \\
7 & $33-36$ & 31.95 & - & 0.76 \\
8 & $51-54$ & 33.51 & - & 0.75 \\
9 & $59-62$ & 67.66 & 43.19 & 0.00 \\
10 & $60-63$ & 359.12 & 0.30 & 0.26 \\
11 & $78-81$ & 36.06 & - & 0.00 \\
12 & $84-87$ & 256.61 & 3.29 & 0.13 \\
13 & $87-90$ & 65.84 & - & 0.74 \\
14 & $96-99$ & 36.42 & - & 0.37 \\
15 & $105-108$ & 23.88 & - & 0.66 \\
16 & $114-117$ & 51.81 & - & 0.19 \\
17 & $123-126$ & 17.38 & - & 0.40 \\
18 & $129-132$ & 11.97 & 0.03 & 0.00 \\
19 & $141-144$ & 50.96 & - & 0.00 \\
\hline
\end{tabular}

acetonitrile. PAHs were analyzed in an Agilent 1260 at the Analytical center of the Faculty of Soil Science, Moscow State University. In total, 13 PAHs were identified: naphthalene, fluorene, acenaphthene, phenanthrene, anthracene, pyrene, chrysene, fluoranthene, benzo $(a)$ pyrene, benzo $(a)$ anthracene, benzo $(b)$ fluoranthene, benzo $(k)$ fluoranthene, and benzo $(g h i)$ perylene.

Data processing. The indicator ratios anthracene/phenanthrene and fluoranthene/fluoranthene + pyrene [17] were calculated for PAHs. Both ratios demonstrate the degree of pyrogenicity or petrogenicity of the studied PAH associations. The values $>1$ and $>0.5$, respectively, suggest a prevalently pyrogenic character; otherwise, prevalently petrogenic one.

Cluster analysis of the PAH concentrations was used for clarifying the affinity of different compounds for one another. The analysis was performed in $\mathrm{R}$ environment using agglomerative algorithm (cluster package).

\section{RESULTS AND DISCUSSION}

The average PAH concentration in peat amounts to $63 \mathrm{ppb}$ with a median value of $34 \mathrm{ppb}$. Most PAH concentrations fall into the range of 10 to $40 \mathrm{ppb}$. The $\mathrm{PAH}$ content is elevated (42 ppb) at the palsa surface and somewhat decreases (to $33 \mathrm{ppb}$ ) with the depth.
Sharp peaks of PAH concentration, amounting to 360 and $260 \mathrm{ppb}$, are observed at depths of 60-63 and 84$87 \mathrm{~cm}$, respectively. In general, the average PAH content in the peat of the lower part of the palsa is higher as compared with its upper part (36 ppb in the lower part versus 28 in the upper part). A minor local increase in the concentration is also observable at depths of 114117 and $141-144 \mathrm{~cm}$. The minimum PAH concentrations were detected at depths of 6-9 and 129-132 cm (Table 1).

The prevalent individual PAH is benzo $(a)$ anthracene (average content, $26 \mathrm{ppb}$ and median, $8 \mathrm{ppb}$ ) followed by benzo $(k)$ fluoranthene and benzo $(b)$ fluoranthene (average content for both, $8 \mathrm{ppb}$ and median, $3.4 \mathrm{ppb}$ for the former and $2.6 \mathrm{ppb}$ for latter). The concentrations of heavy compounds display a distinct depthwise trend: the share of benzo $(a)$ anthracene is dominant to the depth of $60-63 \mathrm{~cm}$, whereas benzofluoranthenes account for the major PAH share in deeper layers (Fig. 1).

The carbon isotope composition in peat displays a weak variation. The maximum $\delta^{13} \mathrm{C}$ value is $-28.05 \%$, being observed at the depth of $63-66 \mathrm{~cm}$ and the minimum $\delta^{13} \mathrm{C}$ value is $-30.5 \%$, being observed at the depth of 33-36 cm (Fig. 2). The average $\delta^{13} \mathrm{C}$ value is $-29.15 \%$. Any distinct trend in the change of ${ }^{13} \mathrm{C}$ content with depth is unobservable. However, lower car- 


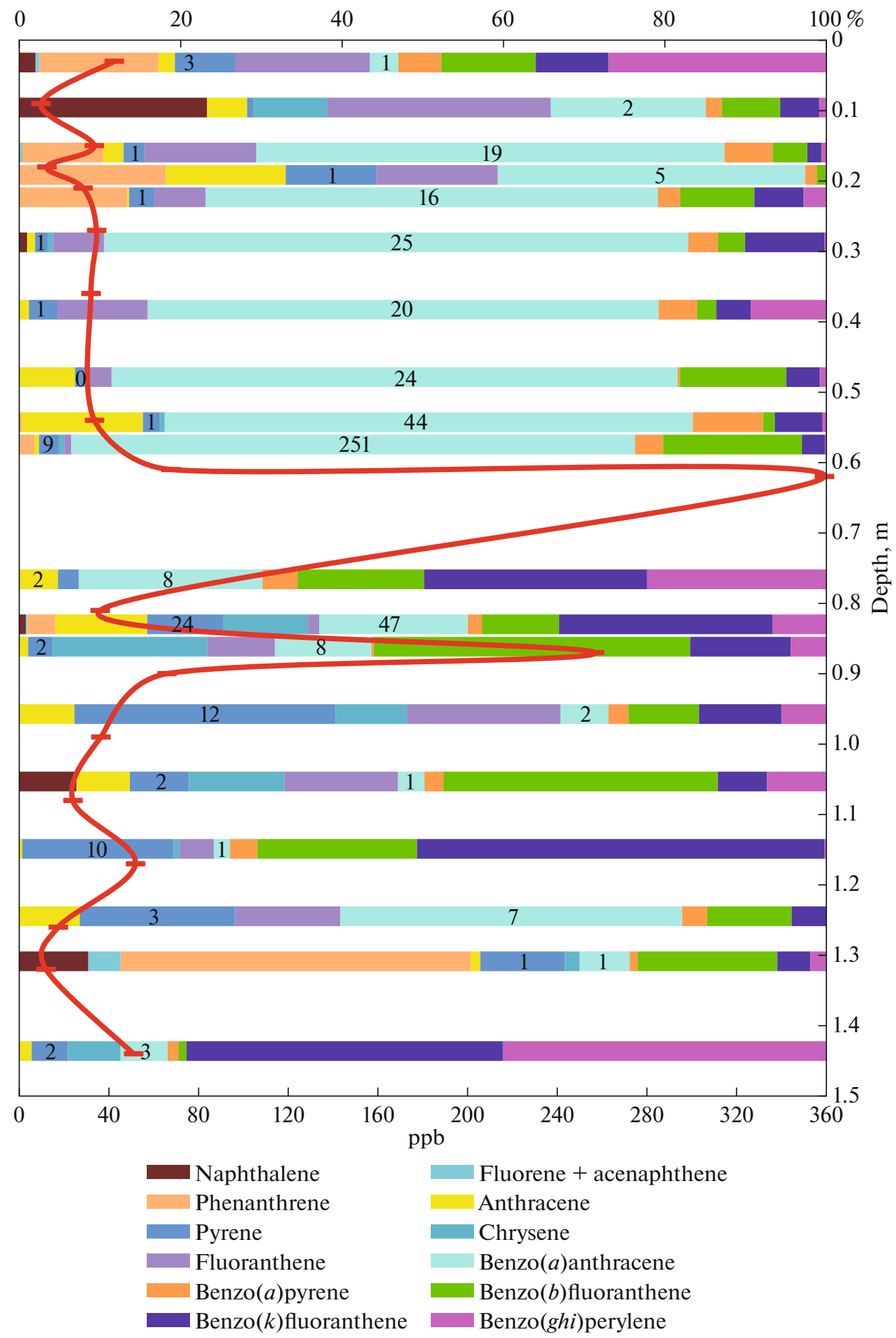

Fig. 1. Shares of individual compounds in the total PAH content in the peat samples of a palsa near Eletsky settlement.

bon isotope values are recorded at depths of 36-39, $57-60$, and $120-123 \mathrm{~cm}$ and higher ones, at depths of $6-9,63-66,87-90$, and $102-105 \mathrm{~cm}$.

An insignificant positive correlation between naphthalene concentration and peat carbon isotope composition ( $r=0.5)$ is observed. The carbon isotope composition displays a weak negative correlation with benzo(a)pyrene. No correlation of the total PAHs with the isotope composition is observed; however, local higher PAH content in the lower part or the profile 


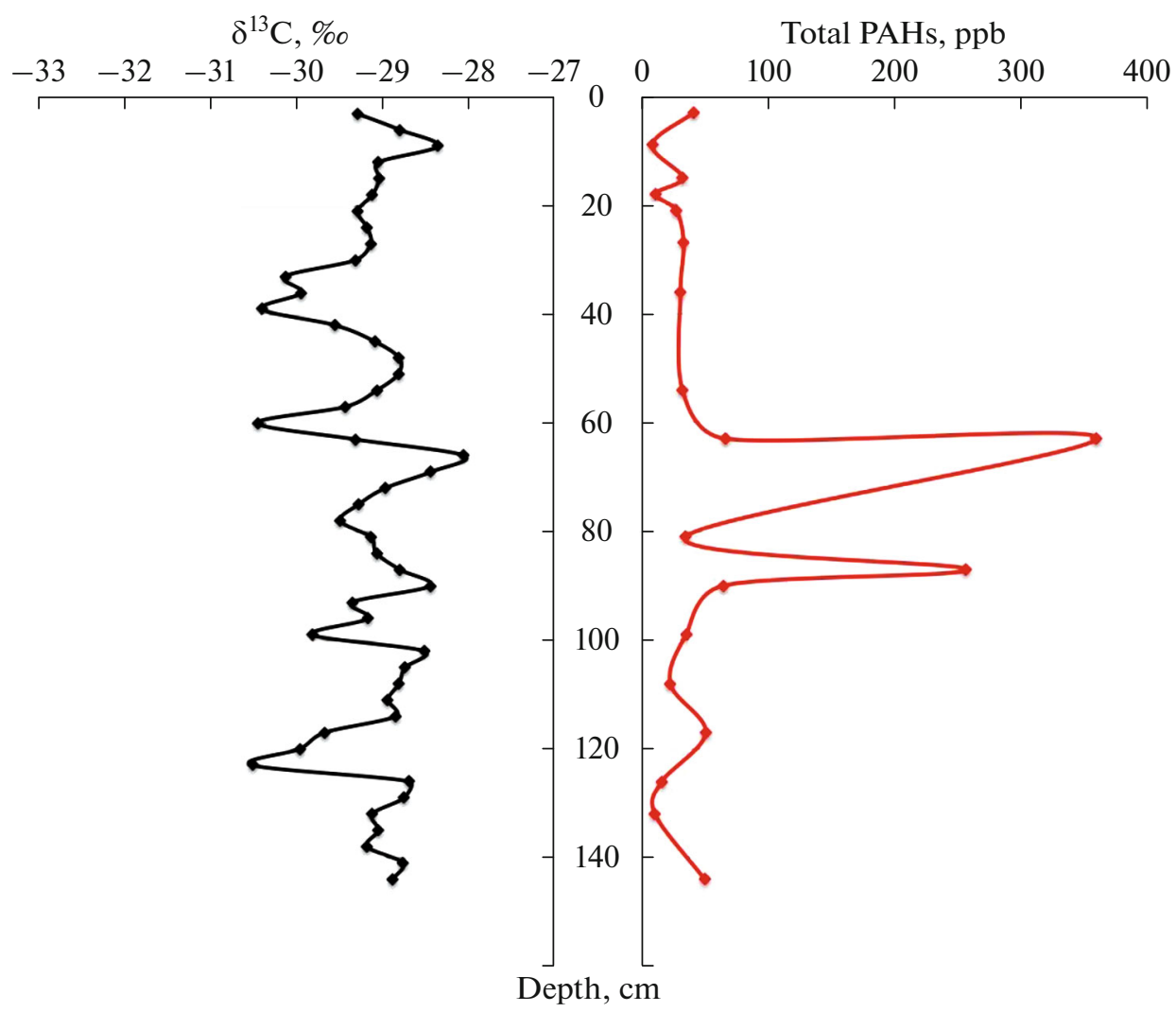

Fig. 2. Carbon isotope composition and total PAH concentration in the peat layer.

correspond to higher isotope values (Fig. 2). An opposite situation is characteristic of the upper part of the profile: higher $\delta^{13} \mathrm{C}$ values correspond to lower PAH concentrations.

Cluster analysis distinguishes three $\mathrm{PAH}$ groups according to their affinity for one another and similar variation: the first cluster comprises anthracene, chrysene, pyrene, and benzo(ghi)perylene; the second cluster contains benzo(a)pyrene, phenanthrene, naphthalene, acenaphthene, fluorene, and fluoranthene; and the third one, benzo $(k)$ fluoranthene and benzo $(b)$ fluoranthene. Benzo $(a)$ anthracene displays no affinity for any of the studied PAHs. A similar clustering was earlier reported [25]; however, a specific position of benzo $(a)$ anthracene and its prevalence in the PAH association have not been earlier observed.

The determined specific features in the distribution, composition, and concentrations of PAHs and carbon isotopes in peat are the result of a joint influence of different factors, including vegetation, matter redistribution during freezing-thawing cycles, climatic effects, and anthropogenic impact.

A comparison of our data to the relevant literature demonstrates that the PAH content in the examined peat palsa is rather low. For example, the PAH concentrations of 160 to $8655 \mathrm{ppb}$ were recorded in the peat palsa near the village of Seida [8] versus the values of $10-360 \mathrm{ppb}$ observed in the palsa near Eletsky settlement. The values recorded in the palsa site are more characteristic of the mineral soils near the village of Seida [7]. In addition, the authors [7] report the prevalence of 2-4-ring PAHs versus the palsa near Eletsky settlement with an absolute prevalence of 5-ring compounds. In the examined palsa, a considerable increase in the PAH content below the active layer bottom was observed, which is analogous to the specific features previously recorded in the peat soil near the town of Inta [9].

The studied territory is near the objects with anthropogenic influence, such as the railroad and an urban-type settlement with furnace heating. These factors affect the PAH content in the palsa sites mainly in the upper peat layers, in particular, the near-surface maximum is most likely determined by this effect, which is confirmed by the presence of a maximum fluoranthene (regarded as a "technogenic" PAH [8]) concentration in the near-surface sample. Most researchers regard benzo $(a)$ anthracene as a technogenic product; note that this compound in the examined palsa was also the prevalent PAH in the peat at the depth of 0 to $60 \mathrm{~cm}$, i.e., to the active layer bottom. Its prevalent content in the entire studied peat layer is most likely associated with the vertical matter transfer mainly determined by the freezing-thawing pro- 
cesses. The indicator ratios at these depths do not unambiguously suggest a pyrogenic origin of the PAH association in the analyzed peat material, indicating a mixed effect of the factors in this case. The deeper peat layers are rather unaffected by the anthropogenic impact and the PAHs in them are of a natural origin.

This also refers to the sharp peaks in PAH concentration (260 and $360 \mathrm{ppb}$ ) at depths of 60-63 and 84$87 \mathrm{~cm}$. This may result from natural paleofires, as the concentrations of pyrene, benzo $(b)$ fluoranthene, and benzo $(k)$ fluoranthene are increased in these layers (according to [36], their production is a characteristic feature of biomass combustion).

The indicator ratios of anthracene/phenanthrene and fluoranthene/(fluoranthene + pyrene) [17] in most samples of the overall peat layer are $<1$ and $<0.5$, suggesting a petrogenic (low temperature) origin of the PAHs. On the other hand, the anthracene/phenanthrene ratio at depths of $60-63$ and $84-87 \mathrm{~cm}$ amounts to 43 and 3, respectively, thereby confirming a pyrogenic origin of the PAHs at these layers.

Presumably, lower PAH concentrations in peat at a depth of $60 \mathrm{~cm}$ are of biogeochemical nature and are to a considerable degree determined by the transformation of plant residues determined by soil processes. As is noted above, several researches agree that PAHs, including the heavy compounds, such as benzo $(g h i)$ perylene and benzo $(a)$ pyrene, can be of a plant origin $[12,15,18]$. However, the indicator ratio of fluoranthene/fluoranthene + pyrene in certain (at a depth of over $60 \mathrm{~cm}$ ) depths in the peat frozen layer suggest a potential contribution of wildfires.

The variation in the PAH composition in the palsa peat in a deeper layer can be also associated with the variation in the composition of plant residues during the second half of the Holocene (as is mentioned above, the radiocarbon age of the peat in the examined palsa at a depth of $0.5 \mathrm{~m}$ is $6400 \pm 60$ years [3]).

The $\delta^{13} \mathrm{C}$ values in the examined palsa are variable along the profile to a lesser degree than PAHs. In general, these values are rather low $(-28$ to $-30 \%$ ) as compared with, for example, the carbon isotope composition of the peatbogs of Central Europe ( -26 to $-28 \%$ ) [20]. Presumably, this is explainable with the specific climatic features: the organic matter of a peatland in cold climate is considerably weaker transformed and, thus, the carbon isotope composition does not become enriched with time. The absence of a depthwise trend of the changes in carbon isotope composition according to $[2,31,32]$ suggests that the examined palsa is not currently subject to degradation and remains in a stable state. In addition, the factor of vegetation can also contribute to the situation since the species composition and the efficiency of photosynthesis change following the specific climate features.

Carbon isotope composition of the peat in the examined palsa displays a considerable variation in the $\delta^{13} \mathrm{C}$ values. Presumably, certain increase of the $\delta^{13} \mathrm{C}$ values suggests some episodes of lower moistening and aerobic conditions. On the contrary, the episodes of a decrease in the $\delta^{13} \mathrm{C}$ values may demonstrate an increase in the hydromorphism, prevalence of anaerobic conditions, and anaerobic degradation of organic matter [4].

The values and variation of the carbon isotope composition of peat are most likely regulated by the variation in vegetation forming the peat. The isotope composition of the peat-forming plants can be rather different. In particular, sedges are characterized by $\delta^{13} \mathrm{C}$ value of $-29 \%$ and mosses by $\delta^{13} \mathrm{C}$ values of -22 to $-20 \%$ [20]. The residues of trees and dwarf shrubs preserved in peat have $\delta^{13} \mathrm{C}$ value of $-25.5 \%$ [ [4]. This suggests that the peat palsa with $\delta^{13} \mathrm{C}$ values of -28 to $-30 \%$ o had been mainly formed with at the expense of grasses.

A comparison of the specific features in a vertical distribution of $\mathrm{PAH}$ concentrations and $\delta^{13} \mathrm{C}$ values in a peatland allows more unambiguously identify the role of paleofires in the formation of peat layer of the palsa. The episodes of paleofires may increase the abundance of ${ }^{13} \mathrm{C}$ relative to the initial matter as well as the concentration of heavy PAHs, especially pyrene, benzofluoranthenes, and benzo $(a)$ anthracene. A drastic increase in the PAH content as well as an increase in the ${ }^{13} \mathrm{C}$ abundance is observed at the depth of $60-66 \mathrm{~cm}$ in the examined palsa profile, which confirms the assumption on the effect of a paleofire at this depth. On the other hand, note that no other coincidences of this kind have been observed.

\section{CONCLUSIONS}

The PAHs in the peat of the examined palsa near Eletsky settlement are mainly represented by heavy compounds, namely, benzo $(a)$ anthracene, benzo $(b)$ fluoranthene, and benzo $(k)$ fluoranthene. The maximums of PAH concentration (360 and $260 \mathrm{ppb}$ ) are most likely determined by paleofires. A large amount of benzo $(a)$ anthracene in the active layer is most likely associated with an anthropogenic factor, that is, the input of pollutants from the atmosphere. Note also a vertical migration of the matter caused by freezingthawing processes, which enhances a relatively uniform distribution of the matter up to the upper boundary of the permafrost.

The carbon isotope composition of palsa peat is determined by the isotope composition of the peat forming vegetation, moistening conditions, and the degree of organic matter degradation.

The carbon isotope composition of the examined palsa peat is relatively depleted $\left(\delta^{13} \mathrm{C}\right.$ values vary between -28 and $-30 \%$ ). These values are close to the isotope composition of herbaceous plants and most likely suggest that peat had been formed mainly of this vegetation type. The variation of isotope composition is noticeable. Presumably, the episodes of an 
increased carbon isotope values suggest the periods with poorer moistening and aerobic conditions, while the episodes of decreased isotope values may suggest the prevalence of anaerobic conditions and anaerobic destruction of organic matter.

\section{FUNDING}

This study was supported by the Russian Science Foundation (project no. 19-17-00126; analysis of stable isotopes) and Russian Foundation for Basic Research (project no. 1805-60272; data analysis).

\section{CONFLICT OF INTEREST}

The authors declare that they have no conflicts of interest.

\section{OPEN ACCESS}

This article is licensed under a Creative Commons Attribution 4.0 International License, which permits use, sharing, adaptation, distribution and reproduction in any medium or format, as long as you give appropriate credit to the original author(s) and the source, provide a link to the Creative Commons license, and indicate if changes were made. The images or other third party material in this article are included in the article's Creative Commons license, unless indicated otherwise in a credit line to the material. If material is not included in the article's Creative Commons license and your intended use is not permitted by statutory regulation or exceeds the permitted use, you will need to obtain permission directly from the copyright holder. To view a copy of this license, visit http://creativecommons.org/licenses/by/4.0/.

\section{SUPPLEMENTARY INFORMATION}

The online version contains supplementary material available at https://doi.org/10.1134/S1064229321070139 and accessible for authorized users.

Fig. S1. Study region on the Google Earth map.

Fig. S2. The examined palsa near Eletsky settlement (photo by N.A. Budantseva).

\section{REFERENCES}

1. Soil Atlas of the Komi Republic (Institute of Biology, Ural Branch, Russian Academy of Sciences, Syktyvkar, 2010) [in Russian].

2. N. A. Budantseva, Ju. N. Chizhova, and Yu. K. Vasil'chuk, "Reflection of the development phases of palsa landscapes of the Bol'shezemel'skaya tundra in the isotopic composition of peat," Arkt. Antarkt., No. 1, 18-31 (2016).

https://doi.org/10.7256/2453-8922.2016.1.21420

3. N. A. Budantseva, Ju. N. Chizhova, L. B. Bludushkina, and Yu. K. Vasil'chuk, "Stable isotopes of oxygen, hydrogen, and carbon and the age of the palsa near Eletsky settlement (northeast of the Bol'shezemel'skaya tundra)," Arkt. Antarkt., No. 4, 38-56 (2017).

https://doi.org/10.7256/2453-8922.2017.4.25087
4. Yu. K. Vasil'chuk, A. C. Vasil'chuk, N. A. Budantseva, E. M. Volkova, L. D. Sulerzhitsky, Ju. N. Chizhova, and H. Jungner, "Radiocarbon age and Holocene dynamics of palsa in the Usa River valley," Dokl. Earth Sci. 384, 442-447 (2002).

5. Yu. K. Vasil'chuk, A. C. Vasil'chuk, N. A. Budantseva, and Ju. N. Chizhova, Palsa of Frozen Peat Mires (Moscow State Univ., Moscow, 2008) [in Russian].

6. Yu. K. Vasil'chuk, J. Yu. Vasil'chuk, A. D. Belik, A. P. Ginzburg, N. A. Budantseva, and A. C. Vasil'chuk, "Cryogenic soils near Eletsky settlement (northeast of the Komi Republic)," Arkt. Antarkt., No. 4, 51-79 (2020).

https://doi.org/10.7256/2453-8922.2020.4.34011

7. D. N. Gabov, V. A. Beznosikov, and B. M. Kondratenok, "Polycyclic aromatic hydrocarbons in background podzolic and gleyic peat-podzolic soils," Eurasian Soil Sci. 40, 256-264 (2007).

8. D. N. Gabov, V. A. Beznosikov, and E. V. Yakovleva, "Accumulation of polycyclic aromatic hydrocarbons in hummocky tundra peatlands under climate change at high latitudes," Geochem. Int. 55, 737-751 (2017). https://doi.org/10.1134/S0016702917060039

9. D. N. Gabov, E. V. Yakovleva, R. S. Vasilevich, O. L. Kuznetsov, and V. A. Beznosikov, "Polycyclic aromatic hydrocarbons in peat mounds of the permafrost zone,” Eurasian Soil Sci. 52, 1038-1050 (2019). https://doi.org/10.1134/S1064229319090035

10. Correction of the General Plan of the Vorkuta Municipal District of the Komi Republic, Vol. 2: Substantiation Materials (Nizhny Novgorod, 2019) [in Russian].

11. A. N. Gennadiev, I. S. Kozin, E. I. Shurubor, and T. A. Teplitskaya, "Dynamics of soil pollution by polycyclic aromatic hydrocarbons and indication of the state of soil ecosystems," Pochvovedenie, No. 10, 75 (1990).

12. A. N. Gennadiev, Yu. I. Pikovskii, V. N. Florovskaya, T. A. Alekseeva, I. S. Kozin, A. I. Ogloblina, M. E. Ramneskaya, et al., Geochemistry of Polycyclic Aromatic Hydrocarbons in Rocks and Soils (Moscow State Univ., Moscow, 1996) [in Russian].

13. A. N. Gennadiev, Yu. I. Pikovskii, A. S. Tsibart, and M. A. Smirnova, "Hydrocarbons in soils: origin, composition, and behavior (review)," Eurasian Soil Sci. 48, 1076-1089 (2015). https://doi.org/10.1134/S1064229315100026

14. M. I. Makarov, T. I. Malysheva, A. A. Goncharov, and A. V. Tiunov, "Isotopic composition of carbon in humus acids of Albic Retisols and Luvic Chernozems," Eurasian Soil Sci. 53, 430-435 (2020). https://doi.org/10.1134/S1064229320040092

15. A. V. Pastukhov, D. A. Kaverin, and D. N. Gabov, "Polycyclic aromatic hydrocarbons in cryogenic peat plateaus of northeastern Europe," Eurasian Soil Sci. 50, 805-813 (2017). https://doi.org/10.1134/S1064229317070092

16. Yu. I. Pikovskii, M. A. Smirnova, A. N. Gennadiev, Yu. A. Zavgorodnyaya, A. P. Zhidkin, R. G. Kovach, and T. S. Koshovskii, "Parameters of the native hydrocarbon status of soils in different bioclimatic zones," Eurasian Soil Sci. 52, 1333-1346 (2019). https://doi.org/10.1134/S1064229319110085 
17. A. P. Khaustov and M. M. Redina, "Geochemical markers based on concentration ratios of PAH in oils and oil-polluted areas," Geochem. Int. 55, 98-107 (2017).

https://doi.org/10.1134/S0016702916120041

18. E. V. Yakovleva, D. N. Gabov, and A. N. Panyukov, "Accumulation of polyarenes in plants of peatlands on the coast of the Barents Sea," Eurasian Soil Sci. 53, 1538-1548 (2020). https://doi.org/10.1134/S1064229320110137

19. G. I. Ågren, E. Bosatta, and J. Balesdent, "Isotope discrimination during decomposition of organic matter: a theoretical analysis," Soil Sci. Soc. Am. J. 60 (4), 11211126 (1996).

https://doi.org/10.2136/sssaj1996.03615995006000040023x

20. C. Alewell, M. Schaub, and F. Conen, "A method to detect soil carbon degradation during soil erosion," Biogeosciences 6, 2541-2547 (2009). https://doi.org/10.5194/bg-6-2541-2009

21. C. Alewell, R. Giesler, J. Klaminder, J. Leifeld, and M. Rollog, "Stable carbon isotopes as indicators for micro-geomorphic changes in palsa peats," Biogeosciences 8, 1769-1778 (2011). https://doi.org/10.5194/bgd-8-527-2011

22. S. van Bellen, M. Garneau, A. A. Ali, and Y. Bergeron, "Did fires drive Holocene carbon sequestration in boreal ombrotrophic peatlands of eastern Canada?" Quat. Res. 78 (1), 50-59 (2012).

https://doi.org/10.1016/j.yqres.2012.03.009

23. R. Benner, M. L. Fogel, E. K. Sprague, and R. E. Hodson, "Depletion of ${ }^{13} \mathrm{C}$ in lignin and its implications for stable carbon isotope studies," Nature 329, 708-710 (1987).

https://doi.org/10.1038/329708a0

24. R. S. Clymo, "The limits to peat bog growth," Philos. Trans. R. Soc. B 303, 605-654 (1984). https://doi.org/10.1098/rstb.1984.0002

25. D. Gabov, E. Yakovleva, and R. Vasilevich, "Vertical distribution of PAHs during the evolution of permafrost peatlands of the European arctic zone," Appl. Geochem. 123, $104790(2020)$.

https://doi.org/10.1016/j.apgeochem.2020.104790

26. M. R. de Souza, F. R. da Silva, C. T. de Souza, et al., "Evaluation of the genotoxic potential of soil contaminated with mineral coal tailings on snail Helix aspersa," Chemosphere 139, 512-517 (2015).

https://doi.org/10.1016/j.chemosphere.2015.07.071

27. N. E. Flanagan, H. Wang, S. Winton, et al., "Low-severity fire as a mechanism of organic matter protection in global peatlands: thermal alteration slows decompo- sition," Global Change Biol. 26 (7), 3930-3946 (2020). https://doi.org/10.1111/gcb.15102

28. E. R. C. Hornibrook, F. J. Longstaffe, W. S. Fyfe, and Y. Bloom, "Carbon-isotope ratios and carbon, nitrogen and sulfur abundances in flora and soil organic matter from a temperate-zone bog and marsh," Geochem. J. 34, 237-245 (2000).

https://doi.org/10.2343/geochemj.34.237

29. M. C. Jones, D. M. Peteet, and R. Sambrotto, "Lateglacial and Holocene $\delta^{15} \mathrm{~N}$ and $\delta^{13} \mathrm{C}$ variation from a Kenai Peninsula, Alaska peatland," Palaeogeogr., Palaeoclimatol., Palaeoecol. 293 (1-2), 132-143 (2010). https://doi.org/10.1016/j.palaeo.2010.05.007

30. A. Khaustov and M. Redina, "Fractioning of the polycyclic aromatic hydrocarbons in the components of the non-equilibrium geochemical systems (thermodynamic analysis)," Appl. Geochem. 120, 104684 (2020). https://doi.org/10.1016/j.apgeochem.2020.104684

31. J. P. Krüger, J. Leifeld, S. Glatzel, et al., "Biogeochemical indicators of peatland degradation-a case study of a temperate bog in northern Germany," Biogeosciences 12, 2861-2871 (2015). https://doi.org/10.5194/bg-12-2861-2015

32. J. P. Krüger, F. Conen, J. Leifeld, and C. Alewell, "Palsa uplift identified by stable isotope depth profiles and relation of $\delta^{15} \mathrm{~N}$ to $\mathrm{C} / \mathrm{N}$ ratio," Permafrost Periglacial Process. 28 (2), 485-492 (2017). https://doi.org/10.1002/ppp.1936

33. Yu. K. Vasil'chuk, A. C. Vasil'chuk, N. A. Budantseva, Ye. M. Volkova, and Ju. N. Chizhova, "Radiocarbon chronology of palsa in the Bol'shezemel'skaya tundra." Dokl. Earth Sci. 393 (8), 1160-1164 (2003).

34. Yu. K. Vasil'chuk, A. C. Vasil'chuk, H. Jungner, N. A. Budantseva, and Ju. N. Chizhova, "Radiocarbon chronology of Holocene palsa of Bol'shezemel'skaya tundra in Russian North," Geogr., Environ., Sustainability 6 (3), 38-59 (2013). https://doi.org/10.24057/2071-9388-2013-6-3-38-59

35. L. Zeh, M. T. Igel, J. Schellekens, et al., Vascular plants affect properties and decomposition of moss-dominated peat, particularly at elevated temperatures," Biogeosciences 17 (19), 4797-4813 (2020). https://doi.org/10.5194/bg-17-4797-2020

36. S. Zuo, R. Li, S. Xie, et al., Paleofire indicated by polycyclic aromatic hydrocarbons in soil of Jinluojia archaeological site, Hubei, China," J. Earth Sci. 21 (3), $247-256$ (2010). https://doi.org/10.1007/s12583-010-0089-x

Translated by G. Chirikova

EURASIAN SOIL SCIENCE $\quad$ Vol. $54 \quad$ No. $7 \quad 2021$ 